Article

\title{
Driving Factors of Smart City Construction in China-An Exploratory Method by Grounded Theory and Empirical Research
}

\author{
Qinghong Cui * and Guangbin Wang \\ School of Economics and Management, Tongji University, Shanghai 200092, China; \\ gb_wang@tongji.edu.cn \\ * Correspondence: 1110262@tongji.edu.cn or tsinghongcui@126.com
}

\begin{abstract}
Driving factors of smart city construction are exploratively studied by grounded theory method based on text sources from journal papers in SCI and CSSCI databases. Initial scale of driving factors about smart city construction is obtained on the basis of above analyses. This paper modifies measuring items of the initial scale with a small sample pretest and reliability test, then forms final items by exploratory factor analysis. According to the above scale, questionnaires are designed to obtain empirical data, and confirmatory factor analysis is used to verify further validity and reliability of the scale. The results show that driving factors of smart city construction include three main dimensions: problem-oriented factors, business- or technology-driven factors and endogenous development requirements.
\end{abstract}

Keywords: smart city; smart city construction; urban sustainability; driving factors; grounded theory; empirical research

\section{Introduction}

Cities around the world are under pressure from population growth, frenetic global economic restructuring, and climatic perturbations[1].Smart cities represent a conceptual urban development model based on the utilization of human, collective, and technological capital for the enhancement of development and prosperity in urban agglomerations [2] . There are at least 3 different positions and perspectives about the emergence of smart city and impetus to its construction. One of the reasons is profit-drive by information and communication technology enterprises. The smart city, as an emerging market with enormous potential, is expected to drive the digital economy forward in the coming years[3]; similarly, the global smart city market is expected to exceed $\$ 1$ trillion by 2016, growing at a compound annual growth rate of 14.2 per cent [4]; and it is also estimated to be of three-digit billion dollars by 2020, with an annual spending reaching nearly $\$ 16 \mathrm{bn}$ [5]. This has triggered Cisco, IBM, HP, and other global information and communications technology (ICT) players to launch their own smart planet and smart city initiatives [6]. Secondly, there is still in fact no general consensus on the meaning of the term smart city [7] and no agreed definition on it [2]; besides, it is currently a generic and optimistic concept for the city of the future and, in fact, no suitably widespread definition has yet been elaborated. And there is still a controversy of the relation among the origin of smart city, smart growth and intelligent city[8]. The third reason is about skepticism of technological determinism. Compared with the concept of digital city or intelligent city, the main focus of smart city is not limited to the role of ICT infrastructure but is mainly on the role of human capital/education, social and relational capital, and environmental issues, which are considered important drivers of urban growth[9]. On the whole, the knowledge and innovation economy is an essential driver of the smart city discourse, especially the knowledge economy, which played a significant role in the emergence of the idea of smart cities[10].

The answer and solution of the above differences need to effectively identify and clearly defined construction driving factors (CDF) of the smart city. Existing literatures about smart city have analyzed reasons and driving forces of smart city construction from different disciplines and perspectives, which contents focus on 2 aspects. (1) The first one is about urban development problems, different contexts and external environment, which mainly include concurrent trends in urbanization, economic growth, technological progress, and environmental sustainability that are the drivers for this newfound urgency [11]. The urbanization emphasizes persistent pressures of urban infrastructures due to the increasing size and proportion of urban population. Economic 
growth is about how to promote innovation and entrepreneurship to stimulate economic vitality by urban agglomeration effect. Technological progress reflects the improvement of urban living and production methods, and environmental sustainability is concerned about climate change, energy resources and environmental protection. In addition to urbanization, resource scarcity, energy shortages, global environmental "weirding" and better economic opportunities, inadequate and deteriorating infrastructure, human health concerns and demand for social benefits are also regarded as driving factors of prompting smart city construction [12]. (2) The other aspect involves in endogenous requirements, especially about urban innovativeness and competitiveness. Ability to innovate is recognized as a key driver of the smart city construction, including human factor, education, learning and knowledge center which are fundamental components of smart city [13]. With the deepening of economic globalization, cities are becoming more and more important frontiers and places that gather, allocate and compete for resources worldwide. Except for urban economic development, the power of smart city construction is paid more emphasis on the competitiveness among different cities and promotion to attractive "creative classes" [14].

Although the existing literatures are relatively fragmented in contents, they greatly enrich research contents of smart city and can be used as important references of quantitative analysis. This article further makes a systematical and exploratory research on the basis of them, which is by using the grounded theory method (GMT). In order to provide advices for the following researches and practices, an empirical research about construction driving factors of the smart city is implemented by scale development, questionnaire design and survey.

\section{Data sources, research method}

\subsection{Research method}

GTM were first developed in the 1960s by Barney Glaser and Anselm Strauss [15], which aims to generate theory by grounding that theory in data rather than verify theory as traditional quantitative research does. Rooted in medical sociology, GTM has spread to wider practitioner fields such as nursing, education, psychology, accounting, business management, and social work [16]. In grounded theory, data analysis has a well-defined process that begins with basic description and moves to conceptual ordering and then on to theorizing, which is accomplished through an elaborate set of coding processes [17]. Coding is the fundamental analytic process used by the researcher, which can be divided into three basic phases: open, axial, and selective [18].

In this paper, GMT is used to make a exploratory research about construction driving factors of smart city by data analysis process of open, axial, and selective coding. The process of data collection and analysis is iterative by constant comparison, refinement and modification. In coding results, categories of the open coding are used to form measuring items in the phase of developing scale; axial and selective coding results are exploited to cluster the items and construct corresponding variables; based on the analyses above, an initial scale is accomplished by expert evaluation. According to the variables and items in the scale, a questionnaire for small sample pre-test is preliminarily developed by combing with principles, steps and formats of questionnaire design. In order to test validity and reliability of the scale, data collected from the small sample pre-test questionnaire survey are used for item purification, reliability test and exploratory factor analysis. According to the above analysis results, the initial scale is made a further modification. The modified scale is used to build the formal questionnaire by repeating the questionnaire design process, from which data collected are used for confirmatory factor analysis.

\subsection{Data sources}

Data sources of this paper are journal articles from Web of Science ${ }^{\mathrm{TM}}$ Core Collection and Chinese Social Sciences Citation Index database. 177 journal articles from the Web of Science are obtained by using the search condition of which titles contain "smart (er) city/cities" from 2005 to 2014, and by the same way, 143 papers are gotten from CSSCI database between 2005 and 2014. Numbers of the data sources per year and their tendencies are depicted in Figure 1. 


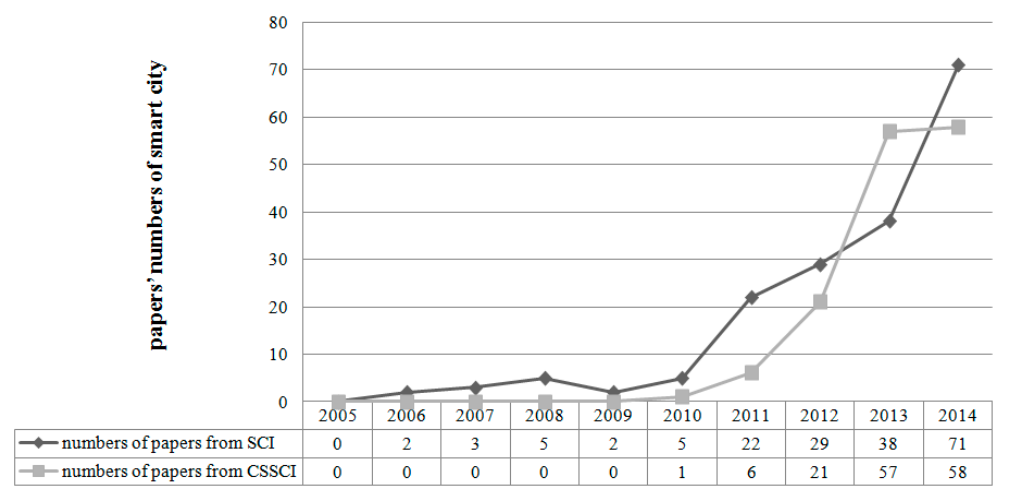

Figure 1. The papers' amounts of smart city: 2005-2014.

As shown in Figure 1, the quantities of journal papers gradually increase year by year. Although the disciplinary distribution of them are complicated, it generally focuses on two major research areas of ICT and urban study (as shown in Figure 2). In addition, smart city research begins to appear in the field of construction project management (CPM), such as the journal of "Automation in Construction" according to the study about ranking of CPM journals (Chau, 1997)[19].

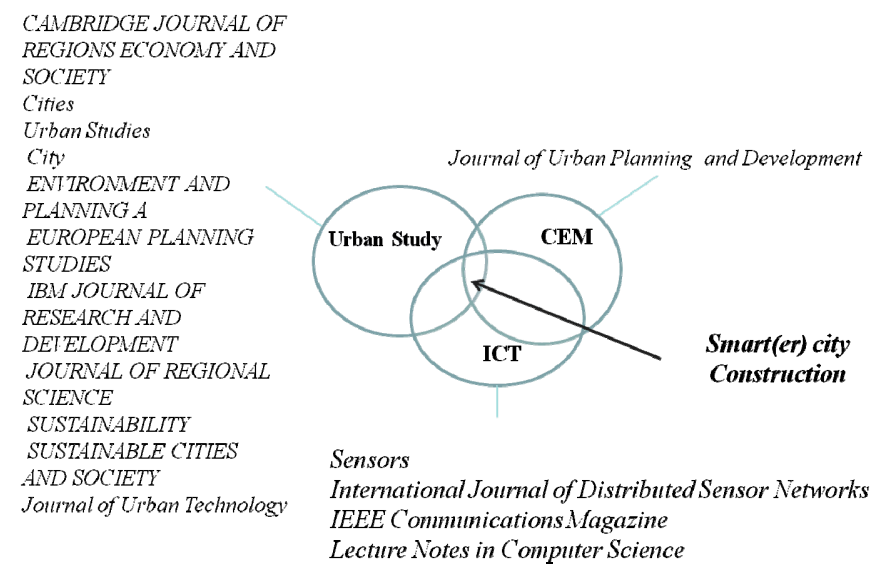

Figure 2. Main journals of the data sources from SCI.

The earliest paper about smart city from the CSSCI database appeared in 2010, and journals related to smart city in China mainly concentrate in these following ones: "Urban Development Studies", "Forum on Science and Technology in China", "Science and Technology Management Research", "City Planning Review" and "Science \& Technology Progress and Policy", which are shown in Figure 3.

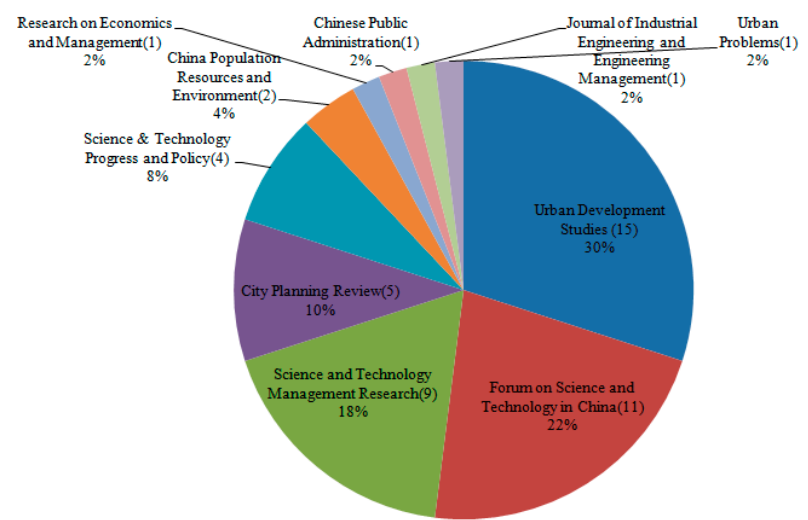

Figure 3. Main journals of the data sources from CSSCI.

In order to facilitate data management and increase traceability of effective data, different data sources are classified and coded on the basis of screening and sorting, which basic format is composed of abbreviation of data source plus the paper's order number. Data source of the empirical study is from the small sample pre-test and formal questionnaire survey, their detailed contents will elaborate in the following corresponding sections. 


\section{Coding process}

\subsection{Open coding}

Open coding is the interpretive process by which data are broken down analytically. Its purpose is to give the analyst new insights by breaking through standard ways of thinking about or interpreting phenomena reflected in the data [18]. In order to avoid confusion due to excessively initial concepts and reduce overlaps between different concepts, initial categories are classified and grouped in Table 1. This paper only chooses one descriptive material of every category for saving space.

Table 1. Results of open coding.

\begin{tabular}{|c|c|}
\hline Category & Descriptions of the data \\
\hline competitiveness & $\begin{array}{l}\text { S004 There are various drivers for the Smart City model in Barcelona, but among all, } \\
\text { fostering competitiveness of the city is the leading one. }\end{array}$ \\
\hline urban population & $\begin{array}{l}\text { S055 The last few years, a significant research effort and technological development have } \\
\text { been devoted to the IoT domain targeting smart city concepts, for various reasons. The second } \\
\text { most notable reason is the population growth and the urbanization trend. }\end{array}$ \\
\hline resources consumption & $\begin{array}{l}\text { SE13 Rapid urbanization creates an urgency and imperative for cities to find smarter ways to } \\
\text { manage the accompanying challenges, such as wasteful energy consumption. }\end{array}$ \\
\hline environmental protection & $\begin{array}{l}\text { C56 Environmental protection is one of (sustainable) development driving factors of smart } \\
\text { city development model. }\end{array}$ \\
\hline economic growth & $\begin{array}{l}\text { SE22 The most obvious driver for smart city development is the economic crisis and the need } \\
\text { to produce more wealth. }\end{array}$ \\
\hline technical diffusion & $\begin{array}{l}\text { S128 (one of) the reason of a city able to be smart is the larger diffusion of mobile devices and } \\
\text { the Internet among citizens. }\end{array}$ \\
\hline attractiveness & $\begin{array}{l}\text { S048 Smart City initiatives can also include human capital investments that are aimed at } \\
\text { fostering a city's capacity for learning and innovation, by supporting and motivating the local } \\
\text { population in education and by improving their own life and attracting and retaining other } \\
\text { valuable inputs from outside. }\end{array}$ \\
\hline climate change & $\begin{array}{l}\text { S054 A number of factors have been identified as major driving forces behind the transition } \\
\text { towards Smart Cities. Changes taking place in the global environment and the changing life } \\
\text { styles of people are viewed to be the two major motivations behind this transformation. }\end{array}$ \\
\hline innovation capability & $\begin{array}{l}\text { S004 Smart City was initiated to promote innovation, create new channels of communication, } \\
\text { facilitate access to information both locally and internationally and improve the efficiency of } \\
\text { public services. }\end{array}$ \\
\hline business value & $\begin{array}{l}\text { S052 Experts point out Smart Cities as an emerging market with enormous potential, which } \\
\text { is expected to drive the digital economy forward in the coming years. The current consensus } \\
\text { value of the IT market for Smart Cities globally is approximately } \$ 35 \mathrm{bn} \text {. }\end{array}$ \\
\hline technical advancement & C56 Technological progress is the technology-driven factor of smart city development model. \\
\hline
\end{tabular}

\subsection{Axial coding}

In axial coding, categories are related to their subcategories, and the relationships tested against data. Also, further development of categories takes place and one continues to look for indications of them [18]. Four core categories are summarized in accordance with correlation and logic sequence among them.

Table 2. Results of axial coding.

\begin{tabular}{|c|c|c|}
\hline Core categories & Categories & Meanings \\
\hline \multirow{4}{*}{$\begin{array}{l}\text { Development } \\
\text { dilemma }\end{array}$} & Urban population & $\begin{array}{l}\text { Urban development pressure due to the increasing urban population, density and } \\
\text { size. }\end{array}$ \\
\hline & $\begin{array}{l}\text { Resources } \\
\text { consumption }\end{array}$ & $\begin{array}{l}\text { Problems of energy and resources shortage, improvement of their consumption } \\
\text { efficiency and wasteful consumption. }\end{array}$ \\
\hline & $\begin{array}{l}\text { Environmental } \\
\text { protection }\end{array}$ & $\begin{array}{l}\text { Pollutant emissions and control, waste treatment and recycling utilization, } \\
\text { environmental damage because of urban growth. }\end{array}$ \\
\hline & Climate change & The impact on global climate change due to increasing urban carbon emissions. \\
\hline \multirow{2}{*}{ Commercial value } & Economic growth & $\begin{array}{l}\text { Innovate new areas of urban economy, meet the needs of urban sustainable } \\
\text { economic growth. }\end{array}$ \\
\hline & Business value & $\begin{array}{l}\text { Commercial potentials, industrial value, development of new-type industry and } \\
\text { information market industrial chains. }\end{array}$ \\
\hline Technical progress & Technical diffusion & Technology and equipment are widely spread, used and diffused in urban areas \\
\hline
\end{tabular}




\begin{tabular}{ccl}
\hline $\begin{array}{c}\text { Technical } \\
\text { advancement } \\
\text { Competitiveness }\end{array}$ & $\begin{array}{l}\text { Constant innovation of technologies, integration among different advanced } \\
\text { technologies, infinite evolution of the technologies' accuracy and granularity } \\
\text { Urban competitive advantage at the background of globalization, the ability of } \\
\text { competing for talents, resources and investments } \\
\text { Attractive and service abilities to innovative enterprise, creative classes, and } \\
\text { various external investments and effective inputs. }\end{array}$ \\
Attractiveness & $\begin{array}{l}\text { Urban learning abilities, innovation levels, entrepreneurial spirits and abilities of } \\
\text { cultivating environment for promoting innovation. }\end{array}$ \\
\hline
\end{tabular}

\subsection{Selective coding}

Selective coding is the process by which all categories are unified around a "core" category, and categories that need further explication are filled-in with descriptive detail[18]. Results of selective decoding are gotten by referring to the analysis approach of these literatures (Wang and Zhang, 2012; Xiao, 2015) [20-21].

Table 3. Results of selective coding.

\begin{tabular}{|c|c|c|c|c|}
\hline Coding process & \multicolumn{4}{|c|}{ Coding analysis results } \\
\hline Open coding & $\begin{array}{l}\text { C11- urban population } \\
\text { C12- resources consumption } \\
\text { C13- environmental protection } \\
\text { C14- climate change }\end{array}$ & $\begin{array}{l}\text { C21- economic growth } \\
\text { C22-business value }\end{array}$ & $\begin{array}{c}\text { C31-technical } \\
\text { advancement } \\
\text { C32- technical diffusion }\end{array}$ & $\begin{array}{c}\text { C41-competitiveness } \\
\text { C42- attractiveness } \\
\text { C43- innovation } \\
\text { capability }\end{array}$ \\
\hline $\begin{array}{l}\text { Axial coding } \\
\text { Selective coding }\end{array}$ & C1- development dilemma & $\begin{array}{l}\text { C2-commercial value } \\
\text { Construction drivi }\end{array}$ & $\begin{array}{l}\text { C3- technical progress } \\
\text { factor }(\mathrm{CDF})\end{array}$ & C- 4 competitive ability \\
\hline
\end{tabular}

The scale about driving factors of smart city construction is developed based on the results of Table 3, in which measuring items are composed of 11 initial concepts from Table 1. In order to ensure content validity of the scale, opinions and suggestions from academic team and relevant industry experts are extensively absorbed to evaluate and improve the contents, pre-test and formal questionnaire design.

\section{Empirical research and results \\ 4.1. Small sample pre-test}

In order to better ensure the validity and reliability of the scale's contents, preliminary questionnaire design and pre-tested are conducted for making a further revision of potential flaws. Questionnaires of the small sample pre-test are mainly issued to relevant institutions and organizations by a "snowballing" way. According to feedback results of questionnaire survey, there are totally 140 sending questionnaires, and 138 of them are retrieved. Effective questionnaires are acquired by eliminating 18 invalid questionnaires, in which are choosing same score in five-point Likert scale, answers are of obvious regularity, or neutral options are chosen too many. The investigation eventually gets 120 effective questionnaires, which account for $85.7 \%$ of the total quantity.

(1) Item purification and reliability test

Before factor analysis, it is necessary to purify and eliminate garbage items. If not, it may lead to multi-dimensional phenomenon, and is thus more difficult to explain the meaning of each factor [22]. Cronbach's alpha coefficient (CAC) and corrected item-total correlation (CITC) test are used to purify items, and suggested values of them are respectively $0.70[23]$ and $0.40[24]$. In test results of scale CDF, every item's CITC value is more than 0.40 ; and deleting any item can not significantly increase the value of CAC, thus every item is reserved. The CAC value of scale CDF equals to 0.923 (greater than 0.70 ), which is indicating that it has good reliability.

Table 4. Corrected item-total correlation and Cronbach's alpha coefficient test.

\begin{tabular}{cccc}
\hline Measuring items & CITC values & CAC values if items deleted & CAC value \\
\hline Urban population & .725 & .914 & \\
Resources consumption & .709 & .916 & \\
Environmental protection & .641 & .919 & \\
Climate change & .682 & .917 & \\
Business value & .833 & .910 & \\
Economic growth & .523 & .926 & \\
Technical diffusion & .805 & .911 & \\
Technical advancement & .785 & .912 & \\
Competitiveness & .706 & .915 & \\
Attractiveness & .653 & .918 & .917 \\
Innovation capability & .673 &
\end{tabular}


(2) Exploratory factor analysis

Because the scale CDF is newly developed, it is necessary to implement exploratory factor analysis to further test its validity and reliability. If there are no theoretical or empirical researches that can support different factors are not related to each other, orthogonal rotation method is better than the oblique one, because results of the previous method are generally easier to understand and interpret [25]. Based on the effective data from small sample pre-test questionnaire survey, exploratory factor analysis of the scale CDF is conducted by the method of equimax rotation in orthogonal rotation. Results of the above analysis are that the value of Kaiser-Meyer-Olkin test equals to $0.840>0.70$ [26], Bartlett's test of sphericity result reaches a significance level, so it is suitable for exploratory factor analysis. There are 3 main common factors extracted by principal component analysis (choosing the maximum equilibrium value method and eigenvalue $>1$ ) of SPSS, and their accumulated variance contribution rate is $79.13 \%$. Accordingly, results of rotating element matrix are shown in Table 5 below.

Table 5. The rotating element matrix of scale CDF.

\begin{tabular}{cccc}
\hline \multirow{2}{*}{ Measuring item } & \multicolumn{3}{c}{ Component } \\
\cline { 2 - 4 } & $\mathbf{1}$ & $\mathbf{2}$ & $\mathbf{3}$ \\
\hline Urban population & $\mathbf{. 8 8 8}$ & .121 & .312 \\
Resources consumption & $\mathbf{. 4 8 8}$ & .546 & .278 \\
Environmental protection & $\mathbf{. 8 7 8}$ & .239 & .068 \\
Climate change & $\mathbf{. 5 5 8}$ & .547 & .163 \\
Business value & $\underline{.554}$ & .332 & $\mathbf{. 6 3 6}$ \\
Economic growth & -.009 & .232 & $\mathbf{. 8 9 1}$ \\
Technical diffusion & $\underline{.607}$ & .284 & $\mathbf{. 5 8 3}$ \\
Technical advancement & $\underline{.568}$ & .222 & $\mathbf{. 6 5 9}$ \\
Competitiveness &.$\underline{445}$ & $\mathbf{. 7 8 4}$ & .063 \\
Attractiveness & .033 & $\mathbf{. 8 1 0}$ & $\underline{.423}$ \\
Innovation capability & .110 & $\mathbf{. 8 1 2}$ & .364 \\
\hline
\end{tabular}

In this paper, factor loads' suggested value is set to 0.40 [26], and when some item has a high factor load value (e.g. more than 0.40 ) on 2 or more factors, a generally feasible solution is to categorize it to the corresponding factor according to the result that researchers have already accomplished in scale development [25]. On these grounds, urban population, resources consumption, environmental protection and climate change are clustered to principal component 1 , which is named by "development dilemma"; business value, economic growth, technology diffusion and technological progress are aggregated to principal component 2 named by "driving factors"; competitiveness, attractiveness and innovation capability are included in principal component 3 named by "endogenous requirements". Based on above analyses and combined with feedbacks of the pre-test, the formal questionnaire is ultimately formed, which is used to collect data for the following empirical research.

\subsection{Confirmatory factor analysis}

Formal questionnaire survey from September 2014 to February 2015 was conducted by traditional and internet-based investigation methods, which totally issued 300 questionnaires, recovered 272 copies and got 213 valid ones that accounted for $71 \%$ of the total. The questionnaires are issued to 43 cities in China, which can be divided into 5 types including municipalities (e.g. Beijing, Shanghai, Tianjin and Chongqing), provincial capitals (such as Hangzhou, Ji'nan, Wuhan, Chengdu and Changchun et al.), independent plan cities (including Shenzhen, Qingdao, Dalian, ), prefecture-level cities (such as Linyi, Yancheng, Zhenjiang, Yantai and so on), and county-level cities (e.g. Zhucheng and Rongcheng). Numbers of people, who engage in the survey from government sectors, enterprises, research institutes and the public are respectively $31,82,51$ and 53 . Most of the respondents have studying/working experience in smart city construction between 0 and lyear, whose amount is 112 ; besides, the quantities of respondents who have studying/working experience of "1 2 years", "2 3 years", "3 4 years" and more than 4 years are respectively $23,18,18$ and 45 . Cronbach's $\alpha$ coefficient test of the scale $\mathrm{CDF}$ and its sub-scale is implemented by using SPSS software, and their results are as follows: Cronbach's $\alpha$ coefficient values of the scale CDF, the sub-scale of development dilemma, driving factors and endogenous requirements are respectively $0.887,0.800,0.824$ and 0.812 , which indicate high reliability level. The KMO and Bartlett test of sample data is further carried out by 
SPSS software, and the results are that the KMO's value is 0.855 , bartlett test of sphericity value reaches a significant level, which further support confirmatory factor analysis of the sample data.

(1) The first-order confirmatory factor analysis

Referring to fitting indices' research findings of Fang (2013) [27], suggested values of them are recommended as follows: $1<\mathrm{X}^{2} / \mathrm{df}<3$, RMSEA $<0.10$, GFI, AGFI, NFI, IFI and CFI $>0.85$. By using AMOS software, confirmatory factor analysis results of the scale CDF are shown in Table 6.

Table 6. Confirmatory factor analysis results of the scale CDF.

\begin{tabular}{|c|c|c|c|c|c|}
\hline Variable & Measuring items & SRW & C.R. & $\rho_{c}$ & AVE \\
\hline \multirow{4}{*}{$\begin{array}{l}\text { development } \\
\text { dilemma }\end{array}$} & urban population & 0.545 & 7.427 & \multirow{4}{*}{0.811} & \multirow{4}{*}{0.522} \\
\hline & resources consumption & 0.743 & 10.399 & & \\
\hline & environmental protection & 0.838 & - & & \\
\hline & climate change & 0.735 & 11.468 & & \\
\hline \multirow{4}{*}{ driving factor } & business value & 0.862 & 15.784 & \multirow{4}{*}{0.819} & \multirow{4}{*}{0.542} \\
\hline & economic growth & 0.543 & 7.930 & & \\
\hline & technical diffusion & 0.572 & 8.587 & & \\
\hline & technical advancement & 0.895 & - & & \\
\hline \multirow{3}{*}{$\begin{array}{l}\text { Endogenous } \\
\text { requirement }\end{array}$} & competitiveness & 0.765 & - & \multirow{3}{*}{0.814} & \multirow{3}{*}{0.594} \\
\hline & attractiveness & 0.833 & 10.831 & & \\
\hline & innovation capability & 0.710 & 9.766 & & \\
\hline goodness of fit & $\mathrm{X}^{2} / \mathrm{df}$ & GFI/AGFI & NFI/IFI & CFI & RMSEA \\
\hline modified model-1 & 3.527 & $0.882 / 0.810$ & $0.875 / 0.907$ & 0.906 & 0.109 \\
\hline modified model-2 & 2.739 & $0.916 / 0.861$ & $0.905 / 0.938$ & 0.937 & 0.091 \\
\hline estimation & yes & yes & yes & yes & yes \\
\hline
\end{tabular}

All of the items' standardized regression weights (SRW) are more than 0.50 , and other model-fit indices conform to the suggested values; every value of average variance extracted (AVE) and composite reliability $\left(\rho_{c}\right)$ is respectively greater than 0.50 and 0.60 , which indicates good reliability and validity. According to the correlation coefficients between different factors in the second modified model and the formula of AVE, the results of discrimination validity are acquired and showed in Table 7.

Table 7. The discrimination validity results of scale CDF.

\begin{tabular}{cccc}
\hline Variable & Development dilemma & Driving factor & Endogenous requirement \\
\hline Development dilemma & $\mathbf{0 . 7 4}$ & & \\
Driving factor & 0.62 & $\mathbf{0 . 7 4}$ & \\
Endogenous requirement & 0.60 & 0.69 & $\mathbf{0 . 7 7}$ \\
\hline
\end{tabular}

As shown in the table above, every square root of the AVE value is more than the correlation coefficient values that are in the row and column where the AVE value locates, which indicates good discrimination validity.

\section{(2) The second-order confirmatory factor analysis}

Due to moderate and high degree of correlation among the variables which correlation coefficients are respectively $0.60,0.62$ and 0.69 (as shown in Table 7), a further second-order factor measuring model is assumed also because the first-order confirmatory factor analysis model has a good model-fit degree with the sample data. The results of the second-order confirmatory factor analysis are acquired by using AMOS software to read the sample data and carry on the fitting process, which include that the value of $\mathrm{X}^{2} / \mathrm{df}$ equals to 2.74 , GFI $=0.916$, AGFI $=0.861$, $\mathrm{NFI}=0.905, \mathrm{IFI}=0.938, \mathrm{CFI}=0.937$ and $\mathrm{RMSEA}=0.091$, all of the above values conform to the suggested conditions. On the base of the above test and analysis results, the second-order confirmatory factor analysis model is accepted in this paper.

\section{Conclusion}

By a combination of qualitative analysis and quantitative test, results of the complicated and dynamic driving factors of smart city construction show that motive forces and reasons that make smart city appear and impetus for its construction activities and behaviors are composed with 3 dimensions, which are development dilemma, driving factor and endogenous requirement, and measured effectively by empirical research. First of all, the development dilemma is constituted by urban population, resources consumption, environmental protection and climate change, which is one of the important reasons and the problem-orientated factor. Specifically, The increasing urban 
population leads to a prominent imbalance between supply and demand, especially in these aspects: resources and energy supply, infrastructure load, public service capacity, effectiveness and efficiency of urban management and operation within the city limits. Cities consume large amounts of resources and energy, to innovate development model, which is more resource-saving and higher energy efficiency, has become a more urgent problem of urban development. Urban environmental protection is increasingly becoming a key issue that can not be ignored; in order to reduce adverse effects to environment because of economic growth, it is necessary to develop and create a more sustainable way of urban growth. Climate change is also deemed to an important cause to the construction of smart city. The motivation of seeking to solve urban development problems is obvious due to the restriction of climate change, besides, it becomes particularly urgent to find greener urban development dynamics.

Secondly, drivers of smart city construction contain two aspects of commercial interest and technological progress, which are driven by business value, economic growth, technology advancement and diffusion. Huge market potential, business value from industry development and information market of smart city construction are the profit-driven factors and good reasons why world's major ICT companies implement their smart city plan; besides, urban infrastructure construction will also bring huge market opportunities and further promotion of economic growth. The technologies - especially ICT advancement provide important technical support for the smart city construction, technical progress and innovation can take better solutions for existing problems, or offer possible solutions by breaking through technical restriction. Thereby, solutions that can effectively solve urban problems can promote technical replication and diffusion. Technological advancement and diffusion constitute ICT-driven factors of smart city construction.

Eventually, endogenous requirements include urban competitiveness, attractiveness and innovation capability, which are the internally imperious demands of smart city construction. Especially in the context of globalization, the cities have gradually become important places of global competition, more and more cities regard improving their competitiveness, attractiveness and innovation capability as important impetus and endogenous requirements. The cities not only need to create spaces of survival and development for the public, provide more available urban infrastructures and services, but also further attract capital investment, inputs of human capital and other factors to promote urban economic development, maintain and enhance their competitive advantages and abilities.

\section{References}

[1] Huston, S.; Rahimzad, R.; Parsa, A. 'Smart' sustainable urban regeneration: Institutions, quality and financial innovation. Cities 2015, 48:66-75.

[2] Angelidou, M. Smart city policies: A spatial approach. Cities 2014, 41:S3-S11.

[3] Elmangoush, A.; Coskun, H.; Wahle, S.; Magedanz, T. Design aspects for a reference M2M communication platform for Smart Cities. International Conference on Innovations in Information Technology. IEEE 2013, 204-209.

[4] Nakazawa, J.; Tokuda, H.; Edwards, W.; Ramachandran, U. A bridging framework for universal interoperability in pervasive systems. 26th IEEE International Conference on Distributed Computing Systems, Lisboa, Portugal, 2006, 3.

[5] Dohler, M.; Ratti, C.; Muñoz, L.; Chatzimisios, P. Editorial of ETT Feature Issue: Smart Cities-Trends \& Technologies. Trans. Emerging Tel. Tech. 2014, 25, 1-2.

[6] Vilajosana, I.; Llosa, J.; Martinez, B.; et al. Bootstrapping smart cities through a self-sustainable model based on big data flow. IEEE Commun. Mag. 2013, 51, 128-134.

[7] Neirotti, P.; Marco, A. D.; Cagliano, A. C.; et al. Current trends in Smart City initiatives: Some stylised facts[J]. Cities, 2014, 38, 25-36

[8] Vanolo, A. Smartmentality: The Smart City as Disciplinary Strategy. Urban Stud. 2013, 51(5):883-898.

[9] Patrizia Lombardi; Silvia Giordano; Hend Farouh; et al. Modelling the smart city performance[J]. Inno. Eur. J. Soc. Sci. Res. 2012, 25, 137-149.

[10] Angelidou, M. Smart cities: A conjuncture of four forces[J]. Cities, 2015, 47, 95-106.

[11] Naphade, M.; Banavar, G.; Harrison, C.; et al. Smarter Cities and Their Innovation Challenges[J]. Computer, 2011, 44, 32-39.

[12] Washburn, D.; Sindhu, U.; Balaouras, S.; et al. Helping CIOs Understand Smart City Initiatives: Defining the Smart City, Its Drivers, and the Role of the CIO. Cambridge, MA: Forrester Research, 2010, 1-15

[13] Nam, T.; Pardo, T.A. Conceptualizing smart city with dimensions of technology, people, and institutions. International Conference on Digital Government Research, Dg.o 2011, College Park, Md, USA, June. 2011.

[14] Colin Harrison and Ian Abbott Donnelly. A Theory of Smart Cities. Proceedings of Annual Meeting of the Isss, 2011, 1-15

[15] Larossa, R. Grounded Theory Methods and Qualitative Family Research. J. Marriage Fam. 2005, 67, 837-857. 
[16] Tan, J. Grounded theory in practice: issues and discussion for new qualitative researchers. J. Doc. 2010, 66, 93-112.

[17] Walker, D.; Myrick, F. Grounded theory: an exploration of process and procedure. Qual. Health Res. 2006, $16,547-59$

[18] Corbin, J. M., Strauss, A. Grounded Theory Research: Procedures, Canons, and Evaluative Criteria. Qual. Sociol., 1990, 13, 3-21.

[19] Chau, K.W. The ranking of construction management journals. Cons. Manage. and Econ. 1997, 15, 387-398.

[20] Wang, C.G.; Zhang A.P. Determinants of Professional Identity of Tourist Guides. J. Shandong U. (Philos. Social Sci.), 2012, 108-112.

[21] Xiao, W.; Luo J.L. Structure Model and Scale Development of Women's Career Success. Econ. Manage. J. $2015,37,79-88$.

[22] Wang, Z.F. Urban Resident Tourist Environmental Impacts and Social Culture Impacts Perceptions Questionnaire Development. Manage. Rev. 2011,23, 36-45.

[23] Peng, Y.J. Construction and Research of Customer Participation Scale. Manage. Rev. 2010, 3, 78-85

[24] Fang, G.W.; Liu R.P.; Ma Q.H. Customers' Reactions to Other-Customer Misbehavior and Their Differences. Chinese J. Manage. 2013, 10, 1384-1392.

[25] Wang, B.J. Multivariate analysis: statistical software and data analysis; Peking University Press: Beijing, China, 2007.

[26] Wu, M.L. Questionnaire statistical analysis practices; Chongqing University Press: Chongqing, China, 2010.

[27] Fang, J. Research on the impact of Construction Project Owner's Organizational Culture and Knowledge Sharing on Project Performance; Tongji University: Shanghai, China, 2013.

(C) 2016 by the authors; licensee Preprints, Basel, Switzerland. This article is an open access article distributed under the terms and conditions of the Creative Commons by Attribution (CC-BY) license (http://creativecommons.org/licenses/by/4.0/). 